\section{Discussion}

Relatively few (7.7\%) declined to answer the questionoriginal naire, so we achieved a good representation of those papers accessing the service. The population was unremarkable as a substance misuse group in contact with services, $40 \%$ being severely dependent, the majority being male and over the age of 30 . There was a wide spread of substance use - opioids and alcohol most frequent reflecting the emphasis of treatment within a clinical service. The first issue, of driving habits, shows that few were currently driving, which may be for financial or legal reasons as opposed to actual choice. Most had driven while influenced by either drugs or alcohol and had charges for driving offences, often drink-driving. This would suggest that most would feel safe combining substance use with driving even though legally many are being challenged. The low reporting of the traffic accidents suggests either a fairly high level of driving competence or an underestimation of accidents.

The second aim was to establish the degree of responsibility. Contrary to the above, responses suggest a high level of awareness of safe levels of substance use before driving, with only a small proportion seeing excess drug or alcohol use as safe. Despite this, substance misusers continue to drive following usage, possibly minimising the perceived risks attached to driving while intoxicated. One explanation of this, as proposed by Albery et al (2000), is that:

"Actual experience of driving after taking drugs could create realistic knowledge and hence a more accurate perception or judgement of the different impairing effects of various illicit drugs."

It is standard local practice at the first interview to run through driving issues with each user and so it is surprising that most people reported not being given information about legal matters. This could be explained by the regularly demonstrated poor retention of information following clinical interviews. The Driver and Vehicle Licensing Agency (1999) widely distribute information regarding fitness to drive - group one licence holders (motor car and motor cycles) who persistently use cannabis, ecstasy and other hallucinogens will have their licence revoked for 6 months. This period increases to 1 year in use of amphetamines, heroin, benzodiazepines, cocaine and methadone (except supervised oral methadone users, who are subject to annual reviews). This must be crucial information to impart to such a population.

Comparing the results to those of Albery et al (2000), the two studies show very similar proportions of subjects that held driving licences, had used drugs prior to driving and had driving convictions, although they found a much higher rate of substance related accidents.

This study begins to look at how substance users may assess risks and responsibilities with regard to driving. With increasing prevalence of substance misuse the danger of driving while under the influence of substances merits further investigation. Clinicians have a responsibility to alert their patients to the risks.

\section{References}

AA GROUP PUBLIC POLICY (1998) Drugs and Driving: A Discussion Paper. Basingstoke: AA Policy.

ALBERY, J. P., STRANG, J., GOSSOP, M., et al (2000) Illicit drugs and driving: prevalence, beliefs and accident involvement among a cohort of current out-of-treatment drug users. Drug and Alcohol Dependence, 58, 197-204.

COHEN, J., DEARNALEY, E. J. \& HANSEL, C. E. M. (1958) The risk taken in driving under the influence of alcohol. British Medical Journal, 2, 1438

DEPARTMENT OF ENVIRONMENTAND TRANSPORT (1999) Road Accidents -
Great Britain: 1999 The Casualty Report. London: HMSO. DRIVER AND VEHICLE LICENSING AGENCY (1999) At a Glance Guide to the Medical Aspects of Fitness to Drive. Swansea: Driver and Vehicle Licensing Agency.

RAISTRICK, O., BRADSHAW, J., TOBER, G., et al (1994) Development of the Leeds Dependence

Questionnaire (LDQ): a questionnaire to measure alcohol and opiate dependence in the context of a treatment evaluation package. Addiction, 89, 563-572.
${ }^{*}$ Tim Bradbeer Specialist Registrar in Psychiatry, Jim Ormsby Specialist Registrar in Psychiatry, St James' Hospital, Locksway Road, Portsmouth PO4 8LD, Philip Fleming Consultant Psychiatrist in Substance Misuse, Kingsway House, 130 Elm Grove, Portsmouth P05 1LR

\title{
How many patients self-medicate with St John's wort?
}

\author{
AIMS AND METHOD \\ St John's wort is popularly taken as a \\ herbal remedy, but it interacts with \\ prescribed drugs. The aim of this \\ survey was to estimate the preva- \\ lence of patients self-medicating \\ with St John's wort. All new referrals \\ to a community mental health team \\ over 5 months were asked about any \\ use of St John's wort.
}

RESULTS

Fifteen patients, of 101, had taken St John's wort at some time and of those seven were currently taking it. Patients who used St John's wort tended to be younger and female. Only nine of the 15 patients took it for depressive symptoms and none had received medical advice. One patient was taking an interacting medication.

\section{CLINICAL IMPLICATIONS}

A significant number of patients are taking St John's wort. In order to prevent drug interactions, doctors should ask all patients whether they use it, especially young women who may be on the contraceptive pill. Patients need better education about its risks and benefits and it should be taken with medical advice. 


\section{Introduction}

St John's wort (Hypericum perforatum) is a common herb that has been used medicinally since the times of Hippocrates and Galen, who used it as a cure for intestinal worms. The active compound is hypericin and the herb is commonly taken for depression. It is commonly believed that herbal remedies are 'safer' than synthetic medicines, but we should not assume that the herb is harmless. Two cases of organ rejection have been attributed to a reduction of plasma ciclosporin levels, possibly owing to an effect of St John's wort on cytochrome p450 in the liver (Ruschitzka et al, 2000), and a recent warning by the chief medical officer advised against taking St John's wort with a number of drugs, including theophylline, digoxin, warfarin, ciclosporin, indinavir and the oral contraceptive pill (Department of Health, 2000). The same report also suggested that it is inadvisable for patients to take St John's wort with selective serotonin reuptake inhibitor (SSRI) antidepressants, as the herb may increase serotonin levels. Other side-effects and drug interactions have also been described (Ernst, 1999). We carried out a survey to measure the proportion of new mental health referrals who were self-medicating with St John's wort.

\section{Methods}

The study was conducted by an inner-London general adult community mental health team. All new referrals over a 5-month period were included. The interview took place during the initial assessment and was always performed by a doctor. We asked the patients if they had ever taken St John's wort and if they had taken it in the past 3 months, the dose they had taken, and any other comments. The age and gender of the patients were recorded along with the clinical diagnosis made by the assessing doctor.

\section{Results}

A total of 114 patients were seen and data were obtained for 101 (89\%). We found that 15 had taken St John's wort at some time for psychiatric symptoms. These patients were younger (mean age 31.6 v. 42.7 for the whole group, independent $T$ test $P=0.01)$ and included more female patients ( $73 \%$ compared with $57 \%, \chi^{2}$ test not significant). Eleven had taken the herb in the past 3 months and seven were taking it at the time of presentation. Of the 15 patients that had used St John's wort, nine had depressive symptoms either in isolation or together with anxiety disorders or dysthymia. Six patients self-medicating did not have depressive symptoms.

Most (12) patients had heard of it through family/ friends, one via the media and one from a healthfood shop. None had sought professional advice beforehand and only six were aware of the dose they had taken. One patient suffered a photosensitivity reaction after taking St John's wort for 2 weeks, which resolved when discontinued, a side-effect previously reported (Bove, 1998). Of the seven patients taking St John's wort, one was taking an interacting medication.

\section{Discussion}

A significant number of patients self-medicate with St John's wort before they present to the psychiatric services. Although St John's wort has been used for over 2400 years and is considered to have relatively few side-effects, its clinical profile is changing through interactions with modern medicines.

The two important implications of this survey are the need to educate clinicians and patients. Clinicians need to be aware when prescribing that many patients will already be taking St John's wort. Clinical trials have established the use of hypericum as an antidepressant only and it is as effective as conventional antidepressants in treating mild to moderate depression (Linde et al, 1996). It is a psychotropic drug but we do not routinely ask about its use. It is important we do so because it has interactions with medical drugs and SSRI antidepressants that psychiatrists may wish to prescribe.

This study highlights the need to improve patient education about which illnesses benefit most from hypericum and in what doses. Patients tended not to discuss starting on St John's wort with their doctor, a finding also found in the US (Wagner et al, 1999). The public need to be aware of potential side-effects and drug interactions, as they can perceive St John's wort to be safer than conventional prescription drugs (Wagner et al, 1999). This survey suggested younger women are more likely to use St John's wort. The risk of pregnancy when using the oral contraceptive may not be known by the user.

While these problems might suggest that St John's wort should be prescribed by physicians, it should be noted that some foods also potentiate sub-enzymes of the P450 system, such as cabbage and sprouts (Jobst et al, 2000). St John's wort may be a useful addition to therapeutic options and if the public are educated about its uses and risks then self-medication may be a useful and acceptable choice. However, the risk of drug interactions and side-effects suggests a need either to regulate its use or provide clear information and warnings when purchasing St John's wort.

\section{Declaration of interest}

R.L. has been principal investigator in a trial sponsored by Lilly Pharmaceuticals.

\section{References}

BOVE, G. (1998) Acute neuropathy after exposure to sun in a patient treated with St. John's wort. Lancet, 52, 1121-1122.

\section{DEPARTMENT OF HEALTH (2000)}

Important Interactions between

St John's wort (Hypericum perforatum). Preparations and Prescribed Medicines.
Public Health Link/CMO's Urgent Communication. CEM/CMO/ 2000/04. London: Department of Health.

ERNST, E. (1999) Second thoughts about St. John's wort. Lancet, 354, 2014-2015. 
JOBST, K. A., MCINTYRE, M. ST GEORGE, D., et al. (2000) Safety of St John's wort. Lancet, 355, 575 .

original papers
LINDE, K., RAMIREZ, G., MULROW, C., et al (1996) St John's wort for depression - an overview and meta- analysis of randomised clinical trials. British Medical Journal, 313, 253-257.

RUSCHITZKA, F., MEIER, P., TURINA, M. et al (2000) Acute heart transplant rejection due to St. John's wort. Lancet, $355,548-549$
WAGNER, P. J., JESTER, D., LECLAIR, B. et al (1999) Taking the edge off: why

patients choose St. John's wort. Journal Family Practice 48, 625-619.

Amanda Redvers Senior House Officer, * Richard Laugharne Consultant Psychiatrist, Gunam Kanagaratnam Associate Specialist, Guru Srinivasan Senior House Officer, Department of Mental Health, University of Exeter, Wonford House Hospital, Dryden Road, Exeter EX2 5AF

Psychiatric Bulletin (2001), 25, 256-260

\section{CAMILLE LEMOUCHOUX, HARRY MILLAR AND SIMON NAJI}

\section{Eating disorders in Scotland: starved of resources?}

\author{
AIMS AND METHOD \\ To describe eating disorder services \\ in Scotland. Fifty-two services \\ completed a postal questionnaire. \\ RESULTS \\ Six of the mainland health board \\ areas, with a total population of 1.5 \\ million, were not covered by any
}

\author{
(self-defined) 'specialist' service. \\ Although most services had access to \\ in-patient facilities, we identified \\ only one designated bed in Scotland \\ for eating disorder patients, and this \\ in a non-specialist service. In many \\ other ways, services did not meet \\ published recommendations for the
}

provision of eating disorders services.

\section{CLINICAL IMPLICATIONS}

It is suggested that a national strategy should be formulated, and a model of service provision is proposed.

\section{The study}

In the context of evidence that the incidence of anorexia nervosa (see Eagles et al, 1995; Pawluck \& Gorey, 1998) and bulimia nervosa (Soundy et al, 1995) have increased in recent years, the aim of the study was to describe eating disorder services in Scotland. Other studies have described specialist eating disorder services in the UK (Royal College of Psychiatrists, 1992; Consumers' Association, 1998), but there is little systematic information available about services in Scotland, and none about services provided outwith specialist eating disorder services. The survey was undertaken in light of recommendations produced by the Royal College of Psychiatrists and the Eating Disorders Association (Consumers' Association, 1998). Stage one identified services and individuals through the Scottish Eating Disorders Interest Group (SEDIG) contact list and by telephone enquiries at NHS trusts. Stage two comprised a postal questionnaire survey of services and individuals identified in stage one.

\section{Findings}

Stage one identified 258 individuals for the questionnaire survey. Several professionals within a service may have received questionnaires to maximise coverage, in which case they were asked to collaborate to ensure the return of at least one questionnaire, and only one complete questionnaire per service was retained for analysis. After excluding duplications and very incomplete returns, 52 questionnaires describing discrete services were analysed. In addition we obtained limited information about a few
Throughout this report, therefore, the denominators for the calculations of percentages vary accordingly.

\section{Numbers and types of services}

Eighteen (35\%) services were designated general adult psychiatry, 10 (19\%) clinical psychology, 12 (23\%) child and adolescent, four (8\%) dietetic and eight (15\%) identified themselves as 'specialist' services. Of these, one was a psychiatric service, one a team within a regional psychiatric service for adolescents and families, one a child psychiatry service and one was within a community mental health team. The remaining four did not further define their service. Health board distribution of services is shown in Table 1. Population sizes served varied considerably. Six of the 12 mainland Scottish Health Board areas, representing a total population of 1.5 million, were not covered by any 'specialist' service.

Outwith the NHS, we identified two counsellors, a development worker, a postgraduate research student and self-help/support groups in nine cities and towns in Scotland.

\section{Patients}

The numbers of patients seen by each service in 1997 varied greatly, with a median (interquartile range) of 16 (30\%). Four 'specialist' and three non-specialist services reported more than 25 patients seen in the year.

For the year there were 87 reported admissions, of which 71 were of anorexia nervosa. Two services admitted a total of three patients under sections of the Mental Health (Scotland) Act.

General practitioners contributed $71.5 \%$ of referrals, and psychiatrists $8 \%$. Very few $(3.5 \%)$ referrals were deemed by services to be inappropriate, but 18 (43\%) 